\title{
Practical Issues in Mobile Education
}

\author{
Marguerite L. Koole \\ Athabasca University \\ mkoole@athabascau.ca
}

\begin{abstract}
Practitioners interested in integrating mobile technology effectively into distance learning programs need to consider both the benefits and limitations of such devices. This paper outlines some major limitations of mobile devices and suggests strategies to mitigate them such as chunking information, using appropriate organizational techniques, reducing the number of required actions, and improving ease of use. Properly planned integration of mobile technology also offers some distinct advantages. Learners can benefit from a dynamic and flexible learning environment with anywhere, anytime access to people and information. Practitioners can use these features to help learners enhance their skills in assessing the relevance and appropriateness of information for use in practical settings.
\end{abstract}

\section{Introduction}

In addition to accessing a variety of human and data resources, mobile learners are better equipped to assess and select information relevant to their lives and learning goals. Mobile learning, however, is constrained by mobile device characteristics as much as it is enabled by them. For many, the phrase mobile learning often evokes images of clamshell cellular telephones with tiny screens and limited options. It conjures sentiments of frustration associated with learning cryptic text messaging shorthand. Others imagine fumbling with a stylus to trigger touchscreen buttons and hyperlinks too tiny for any normally sighted person to read. Fortunately, there is a growing variety of mobile devices available that now match the flexibility and portability of mobile devices to the psychological and physical comfort formerly considered lacking. Ultimately, the degree of constraint or comfort is dependent upon the hardware and software configurations. It is also dependent upon adjustments in teaching and learning strategies. This paper outlines important issues in mobile learning including physical limitations, transparency, customization of content, information access, cognitive effects, and social implications.

\section{Limitations of Mobile Devices}

Handheld computers were originally designed to complement desktop computers rather than replace them [1, 2]. It is not clear if this approach was taken because of inherent constraints in computer technology, but it has resulted in some of the constraints that challenge us today. Some of the most cited criticisms of mobile devices include the small screen sizes, awkward input methods, limited output capabilities, weak processing power, limited memory, difficulty navigating, and difficulty scanning through text [3-5]. Because of these limitations, it can be challenging to use mobile devices in ways in which they were not originally intended.

The results from various studies suggest that mobile devices cannot yet replace larger, more powerful computers. Waycott and Kukulska-Hulme found that regardless of how pleased students were with PDAs, they still preferred to use a laptop because of the greater processing power, screen size, and available functions [3]. The students indicated that PDAs were useful, but as "another resource amongst many" [3]. The results from Koole's study support the view that mobile, wireless handhelds will remain complementary to the larger desktop and laptop computers. While the expert reviewers in Koole's study openly selected and recommended to their colleagues the Dell Axim X50v PDA and the Palm Treo 600 smartphone PDA, they clearly indicated that this recommendation was conditional upon the situation. In addition, they repeatedly commented that serious work and serious study would be easier and most efficient on a regular desktop computer. 


\section{Transparency of Mobile Devices}

The limitations of mobile devices also impact their transparency. Transparency is measured by the amount of time the user must focus on actual device usage compared with the amount of time he or she can focus on cognitive tasks. For example, if navigation or methods of input are cumbersome, then the learner must transfer his or her attention from the learning task to device operation. In such a case, the device would be more opaque than transparent.

It is important to provide students with highly intuitive tools permitting them access to appropriate information sources. Such tools should reduce, or at least, should not add cognitive load. In the study by Waycott and Kukulska-Hulme, the learners commented that they felt disoriented reading electronic documents on PDAs [3]. The students felt that they had a better sense of context from paper documents; that is, they could more easily determine the length of a document and their progress through the paper documents given the associated visual and tactile cues. Some learners may suffer from reduced psychological comfort and may find themselves spending unnecessary time trying to become better oriented with reading materials delivered on mobile devices. Again, this is a sign of opaque technology.

There are ways of increasing transparency. One way is to reduce the number of actions required to complete a task [6]. Long and detailed set-up procedures cause the user to shift his or her focus to the device rather than the learning tasks. Another way to increase transparency and decrease cognitive load is through the automation of procedures that make common functions easier and more efficient. For example, some PDA software will attempt to complete words based on the first few characters that the user selects. This process can help to speed up data input because the user need not type complete words. In addition, if a device can perform repetitive and mundane tasks more accurately and quickly than the user, the user will be able to concentrate on higher level tasks [7]. For example, some word processor applications will correct simple typing errors as they occur. This releases the writer to concentrate on the content or more demanding aspects of writing such as grammatical, structural, and stylistic issues. These techniques may be particularly important when learners are using mobile devices with limited input capabilities.

\section{Customization and Chunking of Course Materials}

Some researchers and practitioners have attempted to overcome the limitations of small mobile devices by customizing course materials. The small screen size, limited navigation, and loss of contextual information of the course materials in addition to unintuitive technology can lead to a fragmented and frustrating learning experience [1]. Therefore, the selection of instructional strategies and development of course materials will depend on a variety of issues such as the capabilities of the devices for which the lessons are targeted, the type of information to be learned, the needs of the learners as well as the pedagogical philosophies of the practitioners.

One technique to consider is chunking materials into meaningful but complete units [8]. The amount and configuration of information within the chunks must be considered in relation to how much information learners are likely to retain. Miller suggests that people are capable of retaining approximately seven chunks of information, give or take two[9]. In addition, the patterns of data within the chunks can be influenced by an individual's familiarity with the information as well as the patterns themselves. The granularity of the chunks must be determined in light of the type of content as well as the context of the content. For example, Kommers claims that unlike factual information, discursive information cannot be taken out of context [10]. Therefore, content developers need to provide summaries, annotations, or other techniques in order to make logical connections between chunks of data.

Indeed, it is prudent to consider the use of summaries, annotations, advance organizers, as well as appropriate chunking and organization of content whenever developing content for any platform or device. However, some mobile devices may require more customization and chunking of content than others by virtue of their physical characteristics as well as their input and output capabilities. Koole found that devices equipped with Windows XP or MacIntosh operating systems required the least content customization [11]. These devices, for the most part, permitted users to access a broad array of multimedia objects and a variety of file types. In addition, input and output could be enhanced by attaching peripherals. The Palm Treo and the Dell Axim PDA, however, had the smallest monitors and did not display information in the same way as desktop computers. Online materials, in particular, were difficult to read on the smartphone and PDA forcing users to scroll through 
learning management systems and frame based sites with difficulty. Koole concluded that the greatest need for content planning and chunking was for PDAs rather than devices equipped with Windows or MacIntosh operating systems.

\section{Flexibility of Mobile Devices}

While researchers in education still debate whether or not technology can influence how people actually learn $[12,13]$, aspects of technology can influence the flexibility with which learners access information and move to different study areas. Flexibility of time and place is currently viewed as highly advantageous to distance learners. Waycott and Kukulska-Hulme suggest that "distance education students typically have to fit their self-managed learning activities around other tasks, such as work and family commitments” [3]. In their study, the respondents documented accessing their course materials in a large variety of situations including traffic jams, work meetings, and at home with children nearby. They also commented on the advantages of being able to carry their course materials around in a "small, lightweight device" [3]. Fagerberg and Rekkedal also found in their research that students could access a variety of systems with their PDAs and that the PDAs permitted them to work while in transit, at home, or at the office [14]. They concluded that the greatest benefit to distance education was the greater flexibility for online study and that the biggest challenge for online study is, rather, in the planning of instruction for higher level learning goals.

Large personal computers connected through cables to communications networks and to a myriad of peripherals such as printers, microphones, speakers, monitors, mice, and other devices reduce the flexibility with which learners can move within their environments [14]. Laptops have eased this problem greatly, but are often still heavy and fragile. The seven mobile devices reviewed in Koole's study all weighed less than 1.5 kilograms and each could fit easily into a backpack [11]. Moreover, many of the devices fit easily into a handbag, and some into a shirt pocket. All were wireless; that is-users could access the Internet without connecting cables to telephone or Ethernet lines. The the Mac Mini in Koole's study was rated as the least portable of all seven devices. In order to use the Mac Mini, it must be plugged into an electrical outlet for power. In addition, the user must connect it to a monitor, keyboard, and mouse. These requirements limit its portability and, hence, the flexibility with which a learner can move to different environments. The Palm Treo 600 was rated the highest for portability. It is an extremely lightweight device, weighing a mere 167.6 grams, and can fit easily into the palm of one's hand. In use, it requires virtually no cables nor peripherals. The other five devices in Koole's study rated between these two extremes. There was an inverse relationship between the number of cables and peripherals necessary for basic operation and the perceived mobility of the device.

Another way to view flexibility is in terms of the malleability of the device to conform to new needs. According to Vygotsky's [15] definition of mediation, as learners interact with each other, their environments, tools, and information, the nature of the interaction itself changes. That is, patterns of interaction and the way students study will change in relation to these elements. In addition, the demands that students place upon the tools they use will also change. This is the basis of the task-artifact cycle: the tools themselves introduce possibilities and constraints that, in turn, redefine the uses for which the artifact was originally intended [16]. Therefore, as learners use mobile devices more, the devices will alter how they perform various learning tasks. In the process, the learners may attempt tasks or demand capabilities that were not originally envisioned for the device.

\section{Information Access}

In addition, to physical mobility, Hoppe et. al. (2003) also suggested that flexibility is related to the ability for users to interact socially and to transfer information between devices through wireless technology. Ways of transferring information and interacting socially include composing, sending, and receiving e-mail or written documents, browsing the Internet, accessing multimedia objects, accessing learning management systems, and using synchronous communications tools. Information access and social communications via technology over a distance are processes complementary to portability, but enable information and social contacts to come to the user rather than forcing the user to move to the information sources.

During Koole's study, the Palm Treo 600 as well as the devices running the Windows XP operating system (the Sony Vaio U71/P, the OQO, and the Toshiba Libretto U100) rated highly for information access [11]. The Treo offered telephone and Internet connectivity through cellular telephone technology (GSM) and, therefore, offered large ranges for access to information from anywhere. The Windows XP 
devices offered several different methods of connecting to various systems: WiFi, Bluetooth, and Ethernet cables. Koole noted a direct relationship between the ubiquity of network access and the perceived ability to access information.

In their study of undergraduate students and the effects of ubiquitous access to wireless networks, Grace-Martin and Gay concluded that "the existence of ubiquitous network access may significantly alter a student's use of a laptop computer" [17]. Waycott and Kukulska-Hulme also concluded that the availability of wireless networks played a significant role in whether or not some features were used—such as e-mail [3]. The researchers predicted that "as wireless networks become more widespread then the device will become more fully functional in more settings. It is likely that acceptance patterns of use would change considerably" [3]. One might suspect, then, that devices which offer more efficient means of connecting to social and computer networks may have a greater impact upon how students study and interact with one another. Conversely, devices with smaller transmission ranges or fewer and more cumbersome methods for connecting to systems may have a lesser impact upon studying and social interaction.

\section{Cognitive and Social Advantages of Mobile Device Use}

Access to information anytime, anywhere combined with the flexibility to move or study within different environments can have additional benefits beyond merely accumulating information. While learners can respond to pre-defined lessons and solve pre-set problems, they can also "find their own problems" [18]. Learners, for example, can access information sources normally outside their geographic, social, or cultural boundaries - in essence, permitting them to discover new concepts, procedures, and challenges. Learners can also generate and contribute new information as they move with their device(s) through their physical and virtual space [2]. Because of their unique perspectives as individuals who are situated within unique geographic and cultural locales, learners have the opportunity to integrate their perspectives with those of others in equally unique situations. In some cases, concepts and procedures developed for specific purposes can be applied to new situations. Learners today must be able to not only memorize facts and information, but must also be able to locate information or create appropriate solutions [18]. Technology can, therefore, become a tool for the access, exchange, and creation of appropriate information [2]. Therefore, devices that offer the most flexible ways to connect with a variety of systems should, in theory, assist students in locating and sharing information that will permit them to solve a variety of problems.

The development of instructional methods that encourage learners to share and discuss their thoughts with instructors and other learners can lead to more effective collaboration and co-construction of knowledge. Zurita and Nussbaum [19] conducted a study in which first graders learning to read were given handheld devices loaded with a software application designed to force students to share discrete syllables in order to build words. The study demonstrates how social dependencies can be built into software applications and, by extension, educational activities.

Increased social interaction can also help learners cope with the abundance of knowledge that is characteristic of today's Internet culture. As the volume of information on the Internet and within other systems grows, learners must develop better skills to help them identify relevant and accurate information. Reduction of information noise and cognitive load is related to increased ability to recognize patterns and relationships between bits of information. The ability to process information in a timely fashion is imperative because as the quantity of information increases, it can affect the relationships, patterns, relevance, and accuracy of specific pieces of information.

Hypothetically, through mobile technology, learners can more quickly and efficiently access information, but they can also reach other learners as well as subject experts. Learners, can, therefore seek the assistance of others when they need to evaluate, organize, or locate appropriate information. Both Kommers and Marra recognize the importance of guiding students through these vast oceans of information $[7,10]$. Brown suggests that teachers must adapt to become coaches or mentors who assist learners to navigate through, select, and manipulate information; that is, they must help learners learn knowledge navigation [20]. Mobile devices, in theory, should permit learners to connect socially with others and should, therefore, have an impact on their ability to navigate information more effectively.

\section{Conclusion}

Some important considerations in selecting appropriate mobile technologies for distance education include understanding the limitations of the devices and how those limitations may affect practical use in learning environments. 
In addition, the practitioner must know the purpose for which the devices will be used. Practitioners must also carefully consider the content itself. Properly displaying and chunking content will help to reduce cognitive load on the learner. Ultimately, the mobile devices selected for educational purposes must be easy to use, flexible, reduce rather than increase cognitive load. These criteria will affect the learners' psychological and physical comfort levels. Mobile devices ideally should also permit increased information access, and, if possible, allow enhanced social interaction for exchange of information and opinions among learners and experts. Such strategies will assist learners in navigating through information and will help them develop strategies for determining the relevance and accuracy of such information.

\section{References}

[1] D. Keegan, "The future of learning: ZIFF papiere 119: From eLearning to mLearning," [Online document], 2002, [Cited 2003 October 25], Available HTTP: http://www.fernunihagen.de/ZIFF/ZIFF_PAP_119.pdf.

[2] C. Staudt, Changing how we teach and learn with handheld computers. Thousand Oaks, CA: Corwin Press, 2005.

[3] J. Waycott and A. Kukulska-Hulme, "Students' experiences with PDAs for reading course materials," Personal Ubiquitous Computing, vol. 7, pp. 30-43, 2003.

[4] Kinshuk, "Adaptive mobile learning technologies," [Online document], 2003, [Cited 2005 February 3], Available HTTP: http://www.globaled.com/articles/Kinshuk200 3.pdf.

[5] C. Shepherd, "M is for maybe," [Online document], n.d., [Cited 2005 January 20], Available HTTP: http://www.fastrakconsulting.co.uk/tactix/features/mlearning.ht m.

[6] B. Shneiderman and C. Plaisant, Designing the user interface: Strategies for effective human-computer interaction, 4th ed. Toronto: Pearson Education Inc., 2005.

[7] R. Marra, "Chapter 6: Human-computer interface design," in Hypermedia learning environments, P. Kommers, S. Grabinger, and J. Dunlap, Eds. Mahwah, NJ: Lawrence Erlbaum Associates, 1996, pp. 115-136.

[8] M. Ally, "Multimedia information design for mobile devices.," in Encyclopedia of
Multimedia Technology and Networking., M. Pagani, Ed. Hershey, PA: Idea Group Inc., 2005.

[9] G. A. Miller, "The magical number seven, plus or minus two: Some limits on our capacity for processing information," The Psychological Review, vol. 63, pp. 1-14, 1956.

[10] P. Kommers, "Chapter 3: Research on the use of hypermedia," in Hypermedia learning environments, P. Kommers, S. Grabinger, and J. Dunlap, Eds. Mahwah, NJ: Lawrence Erlbaum Associates, 1996, pp. 33-75.

[11] M. Koole, "Framework for the rational analysis of mobile education (FRAME): A model for evaluating mobile learning devices," in Centre for Distance Education, vol. Master of Distance Education. Athabasca: Athabasca University, 2006. [12] R. E. Clark, "Media will never influence learning," Educational Technology Research and Development, vol. 42, pp. 21-29, 1994.

[13] R. B. Kozma, "Will media influence learning? Reframing the debate.," Educational Technology Research and Development, vol. 42, pp. 7-19, 1994.

[14] T. Fagerberg and T. Rekkedal, "Enhancing the flexibility of distance educationDesigning and trying out a learning environment for mobile distance learners," in 21st World Conference on Open \& Distance Education, Lifelong Learning in the Networked World. Hong Kong, 2004.

[15] L. S. Vygotsky, Mind in Society: The development of higher psychological processes. Cambridge, Massachusetts: Harvard University Press, 1978.

[16] J. M. Carrol and M. B. Rosson, "Getting around the task-artifact cycle: How to make claims and design by scenario," ACM Transactions on Information systems, vol. 10, pp. 181 - 212, 2005.

[17] M. Grace-Martin and G. Gay, "Web browsing, mobile computing and academic performance," Educational Technology \& Society, vol. 4, pp. 95-107, 2001.

[18] J. Bransford, A. Brown, and R. Cocking, How people learn: brain, mind, experience, and school, expanded ed. Washington, DC: National Academy of Sciences, 2000.

[19] G. Zurita and M. Nussbaum, "A constructivist mobile learning environment supported by a wireless handheld network," Journal of 
Computer Assisted Learning, vol. 20, pp. 235243, 2004.

[20] T. Brown, "Beyond constructivism: Exploring future learning paradigms," [Online document], 2005, [Cited June 10], Available HTTP:

http://www.dreamland.co.nz/educationtoday/ Tom_Brown_Beyond_Constructivism.pdf. 